\title{
O ENSINO DE CINEMA DIANTE DAS NOVAS POSSIBILIDADES INTERATIVAS, IMERSIVAS E INSTALATIVAS DA ARTE, DA MEMÓRIA E DO LIVENESS CONTEMPORÂNEOS
}

\section{Wilson Oliveira Filho}

\section{Resumo}

Esse trabalho pretende chamar a atenção para o ensino de cursos envolvendo o audiovisual, tendo em vista uma nova configuração midiática que torna mais árduo o trabalho com vídeos e novos dispositivos em um contexto educacional. Novos ambientes geram novas experiências e práticas que aqueles que lidam com o ensino e a pesquisa do audiovisual não podem esquecer, quando experiências como o live cinema se adensam. Em suma, interrogamo-nos sobre como a interatividade, a imersão e as instalações multimídia podem de certa forma ampliar as possibilidades em salas de aula. Tentamos refletir sobre perspectivas, dialogando com novos possíveis da arte para o ensino que não excluam interações com os gadgets e demais dispositivos dos alunos.

\section{Palavras-chave:}

Cinema, Arte Contemporânea, Novas Mídias.

\begin{abstract}
Coloquemo-nos no estado de espírito de um jovem estudante, quer dizer, num estado de espírito que, na época tumultuada e agitada em que vivemos, é algo totalmente incrível: é preciso tê-la experimentado para que pudesse parecer simplesmente possível esta ilusão despreocupada, essa tranqüilidade, conquistada no momento e, por assim dizer, estranha ao tempo. (NIETZSCHE, 2003, p.49)
\end{abstract}

A época tumultuada a que Nietzsche faz menção se acelerou. Os jovens estudantes se transformaram e o "agito" em sala de aula precisa compreender nossa estranheza a esse tempo em que a atenção de um estudante está dividida entre suas mensagens no WhatsApp, suas fotos no Instagram, seus affairs no Tinder, seu Facebook ou Twitter e seus fones de ouvido. Diante desse quadro altamente cinematográfico, de imagens, narrativas e sons, acreditamos que o ensino do audiovisual precisa mais e mais compreender uma observação que McLuhan já

\section{Abstract}

This paper tries to turn our attention to audiovisual teaching related courses having in mind a new media configuration that becomes the work with videos and new apparatus harder in an educational context. New environments create experiences and practices that those who deal with audiovisual teaching and researching can not forget when live cinema experiences densify. In short we interrogate how interactivity, immersion and multimedia installations can somehow extend possibilities to classroom. We try to think perspectives by creating a dialogue with new art possibilities to teaching that do not exclude interactions with gadgets or other students devices.

Keywords:

Cinema, Contemporary Art, New Media.

fazia ao rádio, ao cinema e à televisão: "salas de aula sem paredes" disso se trata essas mídias; de salas de aulas com paredes quebradas e extensão dos sentidos apuradas. Em um espaço de aula não mais parece suficiente somente a TV ligada a um vídeo exibindo filmes como ilustração, nem mesmo uma sequência de slides com imagens com ou sem movimento parece conseguir manter diálogo com um aluno que a cada informação pode, com o Google, aprofundar-se ou se afundar em um mar caótico de informação. O aluno busca ou precisa ser convidado a buscar interatividade ou "a possibilidade de responder ao sistema de expressão e dialogar com ele" (MACHADO, 1993, p.250), interagindo com a aula além de suas dúvidas e do dialogismo e de um exame ou trabalho final.

Jacques Aumont (2008, p. 91) pergunta: "Como o cinema ainda é nosso contemporâneo? Ele não 
foi destronado pela televisão, pela internet, pelo vídeo digital, inclusive amador, pela fotografia no telefone, pelo Playstation?" que nossos alunos tão bem navegam. Para essa resposta, percorremos as passagens do entre o cinema e suas possibilidades com a arte. Assim, achamos que a "concorrência" entre os dispositivos dos alunos e professores obedecem ao que Marshall McLuhan ao lado de seu filho Eric McLuhan pensaram como "leis da mídia" (2000). Em uma dessas leis, os autores refletem que um meio é levado à exaustão e se transforma em outro. Tanto cinema quanto aula passam por situação que acreditamos parecidas.

O "cinema de museu" em que filmes, vídeos e outros produtos audiovisuais são medidos em termos espaciais e se tornam instalações, que quase sempre demandam interatividade e que fazem o espectador "cocriar", tornar-se participador como bradava Oiticica, faz a imersão invadir as salas de aula de cursos de audiovisual ou quando 0 audiovisual é requisitado. $A$ imersão nos meios digitais como observa Machado (2009, p.76), a "representação do interator no interior da cena" em sala de aula pode transformar a apresentação de um exercício de um aluno como pode transformar todos os agentes em avatares, além de salas de aulas virtuais de ensino a distância.

A prática contemporânea do live cinema pode ajudar a pensar questões como as colocadas até aqui. Essa performance audiovisual em tempo real feita por artistas que mixam e remixam material, que fundem e confundem práticas, imagens e sons se faz necessária mais e mais para pensar o uso do audiovisual no liveness (na presença, na imediaticidade) de uma aula. Para entender o contemporâneo, Agamben a partir de duas perguntas iniciais (do que e de quem somos contemporâneos), que nos soam próximas a uma tentativa de descrever o cinema contemporâneo, parece sem querer apontar para essa cena imersiva, interativa e instalativa ao vivo. As instalações "se apresentam como um espaço de pesquisa onde as experiências do espectador respondem às dos artistas, onde a representação pode ser testada em todos os estados" (PARENTE, 2013, p. 27) na cena contemporânea. Voltemos nosso olhar a essa contemporaneidade.

Contemporâneo é aquele que fixa o olhar no seu tempo, para nele perceber não as luzes, mas o escuro. “Contemporâneo é justamente, aquele que sabe ver essa obscuridade, que é capaz de escrever mergulhando a pena nas trevas do presente [...]. Contemporâneo é aquele que recebe em pleno rosto o facho de trevas que provém do seu tempo" (AGAMBEN, 2009, p. 62-64). Questão de coragem e de poesia trata-se o live cinema e todo cinema feito nesse olhar fixo de seu próprio tempo que em nossa performance didática às vezes esbarra. Mergulhar a pena nas trevas do presente é como mergulhar a câmera e as ilhas de edição no próprio mundo que o cinema criou e outras vezes destruiu. Tantas mortes e vidas do cinema foram decretadas que teremos a necessidade de atravessá-las com este texto, preferindo falar inicialmente em abalos. Uma arte que finalmente entende a observação de Walter Benjamin (1994) de colocar não mais o original no centro da discussão, mas de colocar a reprodução e não só a representação. Mais que reproduzir, remixar. Malgrado, como observa Salis (2009), a discussão dos direitos autorais, evidentemente. 0 cinema sobrevive para, junto ao vídeo e outras máquinas de visão, reinventar o ensino. Até mesmo os registros de performances de cinema ao vivo legam um trabalho interessante:

[...] tentar entender de que tratam os arquivos encontrados (sejam DVDs ou on line) de um determinado vj ou coletivo de vjs. Trata-se de ficção, de documentários, videoarte, programa de TV, registro de performance [...]. Independente da resposta, e malgrado a discussão sobre direitos autorais, esses arquivos certamente se tornarão conteúdos para outros vjs, outras performances... (SALIS, 2009, p. 228).

O cinema de certa forma sempre foi um remix - um processo que começa na câmera e que na montagem se transforma -, o live cinema, no entanto, se faz a partir disso, se "re-remixa" e por isso arquiva, memoriza o próprio cinema e o audiovisual. Afirmar esse cinema ao vivo em sua articulação com a memória, com a performance em conjunto dos arquivos que circulam pelas máquinas binárias para pensar como uma aula que pensa e usa o audiovisual é proposta desse breve texto. No fundo, o live cinema é uma prática que se pauta pelo efêmero, que se faz a partir de recortes, de camadas e de redes. Que se faz pela invenção (como de certa forma uma boa aula deveria se pensar a propor). Jairo Ferreira parece ter imaginado esse "cinema de invenção, de narrativas sintéticoideogrâmicas e de novas percepções. Anficinema. Nova Grécia Antiga, 
tecnopop, eletrônica. Substituição gradativa da película perfurada pelo teipe tridimensional de alta definição. Cinema sem tela. Cinema sinal, cinema satélite" (FERREIRA, 2006, p. 21-22).

A tentativa de sempre experimentar o cinema como uma arte da simultaneidade, como arte do satélite ou eletrônica tecnopop tem no cinema ao vivo uma outra possibilidade, talvez diferente da "representação integral da realidade", como sintetizou Andre Bazin (1991, p. 87). Não mais o corte, a interrupção para que o espectador não perceba a transição e para que o filme flua, mas um filme que flui de fato devido à performance e ao entendimento da memória como ferramenta ativa no processo cinematográfico e no decorrer de uma aula. O fluxo que o audiovisual pode impor a uma aula é transformar as relações que os alunos fazem com suas máquinas ao objeto em áudio, vídeo e ao mundo que uma aula abre.

Uma nova noção de montagem se estabelece, uma montagem fluida como nos primórdios do cinema, mas ao mesmo tempo, devido às potências do digital, cheia de outras interrupções, paragens, loops, repetições. A simultaneidade das imagens, o liveness e a experiência dessa memória celebram a chance de viver um cinema mais associado a outras artes (e as nossas salas de aulas ainda mal preparadas tecnologicamente), como parecia ser a vocação da técnica embrionária que nascia no final do século XIX, com olhos atentos na recriação de artes já existentes - o cinema remixa desde os primórdios outras artes -, claramente voltada para as tecnologias, para as mídias e especialmente voltada para a memória. Tentativa e chance - que hoje se afirmam com o cinema ao vivo -, fazendo-se de memórias individuais e coletivas, de experiências e criações numa era que, para o cinema e os meios digitais, se pauta mais e mais pelo uso imersivo, instalativo e interativo dos arquivos.

A relação entre cinema e memória é uma relação não só de tangenciamento, mas também de hibridismo que a conserva e, ao mesmo tempo, coloca em xeque as fronteiras entre uma arte, lembrança e esquecimento. 0 cinema ao vivo de certa forma se instaura nesse híbrido ou "encontro de dois meios [...] do qual nasce a forma nova". Um momento de liberdade, de ultrapassagem das fronteiras é esse encontro entre cinema e vídeo, entre cinema e performance, entre cinema e outro meio - "libertação do entorpecimento e do transe que eles impõem aos nossos sentidos (MCLUHAN, 1964, p. 75). Não é a toa que um dos arautos da memória social, o filósofo francês Henri Bergson, versava sobre uma consciência cinematográfica do mundo. Pois se "o caráter cinematográfico do nosso conhecimento das coisas deriva do caráter caleidoscópio de nossa adaptação a elas" (BERGSON, 2005, p. 331), parece-nos que o cinema ao vivo é uma aula pensada em tons performáticos, que cada vez mais consegue captálo (o caráter cinematográfico do conhecimento) e se faz a partir desse caráter. Essa consciência para Bergson ao mesmo tempo estaria engessada no cinema convencional, posto que o tempo do cinema é o de um escoar e de uma passagem suficientes em si como a noção de tempo contínuo. Mais uma vez a associação com a sala de aula nos parece clara. Uma aula é um continuum, um caleidoscópio de memórias, uma matéria que é um conjunto de imagens como observou Bergson.

Não custa lembrar com McLuhan mais uma vez que "o meio é a mensagem" ou como o pioneiro do vídeo, Nan June Paik, que o meio é o meio. 0 vídeo torna o cinema (e hoje outras esferas do que se convencionou chamar digital) uma arte dos extremos, aproveitando a conceituação de Christine Mello (2008). 0 vídeo tem caráter híbrido e

$$
\begin{aligned}
& \text { passa a ter habilidade de recodificar experiências e } \\
& \text { transitar no âmbito das mais diversas manifestações } \\
& \text { criativas. Não por acaso, é senso comum, } \\
& \text { principalmente no circuito da arte, ouvir que "tudo é } \\
& \text { vídeo na contemporaneidade". (MELLO, 2008, p. 27). }
\end{aligned}
$$

Com os circuitos midiáticos tudo se torna aprendizado para além do bem e mal. 0 vídeo se amplia e sua função em sala de aula se torna mais que necessidade,

o vídeo amplia suas funções e passa a ter novas atribuições e abrangências; passa a ser compreendido como um procedimento de interligação midiática e a ser valorizado como produtor de uma rede de conexões entre os mais variados pensamentos e práticas. (MELLO, 2008, p. 27)

Nesse sentido, a história do vídeo ainda está por ser narrada e a sala de aula é um locus para ela. Sua breve memória é uma memória involuntária no sentido proustiano, de algo que irrompe e confunde-nos os sentidos. Essa extremidade do vídeo, apontada por Mello (2008), é de uma 
trajetória inacabada, em movimento, como vértice criativo de variadas práticas. Lembramos do vídeo, pois lembramos do cinema. Essa ampliação ou extensão traz novos desafios ao vídeo, nos dias de hoje. O live cinema é feito com vídeo na maior parte dos casos. Com equipamentos digitais, mas com o suporte que o vídeo ajudou a consolidar. As mídias interligadas tornaram-se "mais" possíveis com as criações em e a partir do vídeo. Suporte de memória, o vídeo torna-se potência para outros e revigorados cinemas e recoloca a questão do arquivo para o estudo das imagens, das estéticas e das tecnologias que sempre pautaram o cinema e que em sala de aula podem ir muito além de recursos.

Como observado por Gene Youngblood, para cunhar a expressão cinema expandido, o termo "videoesfera" é valioso como "ferramenta conceitual para indicar o largo escopo e a influência da televisão em uma escala global em vários campos simultâneos de extensão dos sentidos" (YOUNGBLOOD, 1970, p. 260). Essa escala precisa ser também pensada para usos didáticos, queremos crer. Além do manifesto e de uma série de obras que levavam a alcunha de cinema expandido, incluindo trabalhos como a performer Yvone Rainer e uma obra audiovisual de Beek, "Moviedrome" (1963), aquele se baseia na construção de um teatro semiesférico, no qual multiprojeções nesse semicírculo eram apresentadas para as pessoas deitadas. Essa expansão mais recente do cinema em sua forma ao vivo tem na videoarte - no cinema cósmico de Jordan Belson, nas múltiplas projeções, no cinema videográfico - exemplo de cinema expandido como sua origem. Pela criação de meios de expressão inovadores que eram também usados por outros artistas, videomakers, por exemplo, por um conceito (evidentemente sob forte influência da arte conceitual e do minimalismo) e pela performance, "grande parte da videoarte inicial pode de fato, ser vista como a gravação de uma performance" (RUSH, 2006, p. 87), o cinema expandido alcança a intermídia cinematográfica.

A distinção que Youngblood faz entre cinema e teatro para compreender a noção de cinema intermídia é importante para entender a totalidade do conceito de cinema expandido e como o uso do audiovisual em sala de aula estende as possibilidades do ensino.
No cinema intermídia, as tradicionais distinções entre o que é genuinamente teatral como oposição ao que é puramente cinemático não são mais questões. Embora cinema intermidiático venha individualmente do teatro e do cinema ele não é em uma última análise nenhum dos dois. Qualquer divisão existente entre os dois meios foram não necessariamente construídas, mas orquestradas como oposições harmoniosas numa experiência sensorial maior. [...] não é uma peça ou um filme; e ao mesmo tempo tem elementos dos dois [...] a experiência fílmica não é necessariamente uma projeção de luz e sombras numa tela no final da sala, nem uma experiência teatral contendo um proscênio ou dependente de atores atuando para uma audiência (YOUNGBLOOD, 1970, p. 365).

Essa expansão intermidiática parece-nos importante para entender o liveness e os elementos performáticos que a sala de aula precisa ter para o entendimento do audiovisual no contemporâneo. A esfera do vídeo na esfera do ensino é uma interrelação entre mentes e máquinas.

\footnotetext{
Como o computador, a televisão é uma poderosa extensão do sistema nervoso central. Como o sistema nervoso humano é análogo ao cérebro, a televisão em simbiose com o computador se torna análogo a uma totalidade de cérebros pelo mundo. Estende nossa visão as estrelas mais longe e ao fundo do mar. Permite-nos ver a nós mesmo e por fibras óticas ver dentro de nós mesmos. A videoesfera transcende a telepatia" (YOUNGBLOOD, 1970, p. 260)
}

Essa videoesfera transcendental é composta pela relação entre TV e computador e gera novas estéticas para o audiovisual como a videoarte, as instalações em vídeo, o videoclipe e, hoje, o universo das imagens e sons manipulados em tempo real e o audiovisual para a web que se tornam mais e mais exemplos para quem ensina audiovisual. "Embora a arte da instalação em geral e a videoarte particularmente tenham nascido no ambiente contestatório antimuseus dos anos 1960 e 1970, ironicamente os museus e galerias avidamente absorveram esse tipo de arte" (SANTAELLA, 2005, p. 266); talvez também, como ironia à televisão, os clipes musicais tenham se tornado parte da videoesfera.

A videoarte é atravessada ainda pela questão das narrativas pessoais, como em Bill Viola, que em sua arte começou sua investigação do eu físico e espiritual com vídeos single channel nos anos $70 \mathrm{e}$ 80 (RUSH, 2006, p. 101), culminado em 1979 com "The reflecting pool" - um grande exercício para a memória em forma de vídeo para a consciência 
cinematográfica do mundo. Uma piscina que reflete imagens (uma nova tela para o cinema) e uma edição que ao congelar o mergulho de um homem nessa piscina nos evoca uma memória da própria montagem cinematográfica. De caráter extremamente pessoal - como um jovem pintor experimentando a textura de diversas tintas sobre a tela - Viola penetra na sua própria memória, nessa textura ou poética para tentar compreender o eu e o não eu do misticismo oriental que há muito Ihe interessa (RUSH, 2006, p. 103).

Como mostra Aline Couri, “[...] A videoinstalação vem sendo um meio muito explorado por diversos artistas. Sua peculiaridade é articular dispositivos eletrônicos com espaço, tempo, arquitetura e corpo, envolvendo o observador-visitante espacialmente" (2012, p. 89); essa junção pressupõe que uma memória coletiva também se faz presente. 0 espectador se conecta com o artista para juntos embarcarem por lembranças e esquecimentos da imagem e do som que os cercam. Em aula em um curso de audiovisual ou usando o recurso para articular e trocar conhecimentos esse envolvimento precisa estar presente. Montar instalações para apresentação de trabalhos, avaliações para articular novos tempos e espaços de um curso que lide com o audiovisual nos parece no mínimo curioso.

Da videoarte ao Youtube, do videoclipe ao Vimeo, suportes e estéticas se fundem na cena atual. Cena que, por vezes, desmerece a cultura participativa que o audiovisual na web desponta. Se a querela entre cineastas e videomakers se mostrou desnecessária e a descontinuidade foi reendereçada graças ao hibridismo e à mistura de referências e reverências, o vídeo e a web devem mostrar que mais e mais navegar (agora na rede) é preciso. A web é meio e mensagem para VJs e demais artistas de live cinema, repotencializa o vídeo, o cinema, hibridiza linguagens acentua o caráter pessoal - o lema do Youtube é "Broadcast yourself" ("Transmita você mesmo"), mas também "transmita a si mesmo". Essa pessoalidade, o caráter doméstico, que vem sendo alvo de críticas de autores como Andrew Keen (2009), afirmando que com a web o amadorismo dá as cartas, soa-nos problemática.

Para nossa articulação entre audiovisual, possibilidades interativas, imersivas e instalativas, o material gravado de forma doméstica pode nos dar a versão praticamente "real" de uma festa ou de um passeio, "mas essa versão pode perder insidiosamente todo o sentido dos aspectos que apenas à memória pode preservar: odores e sabores, sentimentos pessoais", observa Armes (1998, p. 15). O que o autor não previa é que a relação entre imagem e memória ganha possibilidades na ambiência virtual. Novas memórias e sensorialidades são despertadas em uma miríade de exemplos na rede. Brassaï (2005) indica uma interessante leitura: a de que Proust ao contrário de criticar a fotografia, como aponta Armes, talvez tenha previsto o fenômeno das imagens na rede. A relação imagem e memória parece-nos beirar um acesso ao Youtube em uso pessoal ou em sala de aula.

Domínio desconhecido, ateliê do passado, abarrotado de campanários, rostos de raparigas, flores murchas, mil outras formas em que toda vida está morta. Logo a memória é para Proust ora uma imensa biblioteca, arquivos "tão vastos de que grande parte nunca iria examinar", ora um tesouro desconhecido escondido bem ao nosso alcance, porém quase inacessível. (BRASSAï, 2005, p. 155-156).

A problemática de que com uma câmera qualquer homem se torna finalmente um produtor de conteúdo - do mais vasto conteúdo, seja da sua lembrança ou do seu esquecimento -, e também participante ativo no processo de fazer arte, de fazer circular a arte nos leva à ideia de que os vídeos no Youtube são também performances. E de certa forma um vídeo no Youtube exibido em sala de aula se torna interativo, imersivo, instalativo. Se torna parte de um novo processo que Serres (2003, p.195) pensa como hominização.

\footnotetext{
Os computadores vieram contemplar esse segmento da hominização. Se essas máquinas podem ser chamadas de universais, elas merecem esse título justamente porque se encontram sob a égide da concentração. Por que temos necessidade de reunir livros, signos, bens de alunos, casas ou atividades, já que computador sempre fez isso?
}

Essa relação entre cinema e tecnologia, de reunião ou coleção de informações é bem enfatizada por Marshall McLuhan que parecia já em 1964 antever fenômenos como o live cinema em sua vocação informacional, performática e arquivística e seu entendimento do audiovisual como sala de aula sem paredes e da concentração de informação, estocagem, inventários criativos.

Em termos de estudo dos meios, torna-se patente 
que o poder do cinema em armazenar informação sob forma acessível não sofre concorrência. A fita gravada e o vídeo-tape viriam a superar o filme como armazenamento de informação, mas o filme continua a ser uma fonte informacional de primeira grandeza [...] Nos dias atuais, o cinema como que ainda está em sua fase manuscrita; sob a pressão da TV, logo mais, atingirá a fase portátil e acessível do livro impresso. Todo mundo poderá ter seu pequeno projetor barato, para cartuchos sonorizados de 8 $\mathrm{mm}$, cujos filmes serão projetados como num vídeo. Este tipo de desenvolvimento faz parte de nossa atual implosão tecnológica. (MCLUHAN, 1964, p. 327)

Não devemos aqui esquecer que o mesmo universo da videoesfera, dessa grande implosão da tecnologia do cinema em outro meio, está contida nesse cinema em expansão, devendo ser referência para o uso inventivo do audiovisual em sala de aula para além das ilustrações.

Jeffrey Shaw avança na discussão do cinema expandido conceituado por Youngblood e dessa implosão tecnológica já falando de um "cinema digitalmente expandido", intermidiático por excelência, pensando novos contextos e exemplos como a realidade virtual, os games locativos e ao nosso ver o live cinema. "Esses novos contextos parecem estar estabelecendo uma plataforma apropriada para outros desenvolvimentos das tradições do cinema experimental" (SHAW, 2005, p.355). Intermídia, entre meios, mutante.

Na verdade, o cinema em trânsito com as artes e pensado em sala de aula se torna uma multidão de coisas.

É o lugar material onde vamos nos divertir com o espetáculo de sombras, na expectativa de que essas sombras nos tragam uma emoção mais secreta do que a expressada pela condescendente palavra "diversão". É também o que se acumula e se sedimenta em nós dessas presenças à medida que sua realidade se desfaz e se altera: aquele outro cinema que é recomposto por nossas lembranças e com nossas palavras até diferir muitíssimo do que a projeção apresentou [...] o cinema é também uma utopia: aquela escrita do movimento que foi celebrada na década de 1920 como a grande sinfonia universal, a manifestação exemplar de uma energia que anima ao mesmo tempo a arte, o trabalho e a coletividade. (RANCIÈRE, 2012, p. 14)

Lugar material traduzido naquilo que se acumula; lugar imaterial que povoa nossas lembranças. Acreditamos que uma nova percepção advém com as camadas audiovisuais criadas pelas performances de live cinema que cada um de nós quando docentes acabamos fazendo em nossas aulas quando usamos um suporte em vídeo.

A reprodução e a experiência se misturam no contemporâneo e em novas produções do cinema e das aulas que se pautam pela presença. E como adverte Gumbrecht (2010, p. 115) essa presença versa "sobre penetrar coisas e corpos [...] constitui um segundo tipo de apropriação-de-mundo, no qual a fusão de corpos com outros corpos ou com coisas inanimadas é sempre transitória e por isso abre necessariamente um espaço [...] à reflexão". Reflexão que o fenômeno da memória como tema dos filmes hoje em dia pode ser indicativa. Embora cineastas como Dziga Vertov nos anos 1920 e Alain Resnais depois nos anos 60 já tenham nos ensinado isso. "O cinema se revela assim [...] o objeto atualmente mais importante daquela ciência da percepção que os gregos chamavam de estética" (BENJAMIN, 1994, p. 194).

Na prática e na percepção que temos do vídeo ao vivo, o loop, a repetição, esse fenômeno da memória por excelência, pode servir para a constituição inteira de um filme. E de certa forma uma aula retorna por vezes como um ciclo, como um loop ou como ruídos. O feedback (tanto de vídeo como sonoro) aponta para uma repetição cheia de nuances dependendo da forma como arranjada pelo artista. O ato de ver (e rever), dinâmica da memória, é trabalhado por VJs na composição visual do live cinema. Quando uma imagem a ser repetida continuamente vem com um defeito técnico, uma linha defeituosa, um problema de cor ou algo do gênero, o erro é incorporado tornando-se parte da estética, ressignificado o loop nessa nova temporalidade do cinema, para além da história na tela, se torna uma "máquina narrativa" (MANOVICH, 2001, p.314). Uma memória repetida do material escolhido é técnica fundamental do remix audiovisual contemporâneo. "A cada momento que o giro de qualquer número termina eu digo a mim mesmo: "Mais uma vez" $\mathrm{E}$ é invariavelmente durante uma dessas repetições que eu fico sensibilizado, por ver repetidamente, pela teatralidade do que acontece na(s) tela(s) em relação com o que é narrado" (BAL, 2009, p. 167).

O cinema dos ciclos é também a realização audiovisual de um objeto elíptico concebido por Duchamp como ready made e convertido em filme "Anémic Cinema" ou nos filmes gráficos de Hans Richter. "O fechado, gravado, que não pode ser 
alterado, e o aberto, cuja imagem se faz ao vivo" (COURI, 2012, p.88) são os dois tipos de loop.

Loop por um lado e ruído ou scratch por outro. O scratch vídeo da Londres dos anos 1980 que "acabou consolidando um circuito de exibição bastante específico, constituído basicamente de casas noturnas, danceterias e bares, locais onde não apenas deve conviver lado a lado com os videoclipes", confunde-se com o próprio vídeo e hoje em dia com o vídeo ao vivo. "Ao optar por esse canal de difusão, os círculos de scratching visavam, sobretudo, escapar ao circuito elitista dos museus e galerias de arte" (MACHADO, 1993, p. 156). Como em algumas videoinstalações ou videoarte e também em filmes de found footage , a repetição ao lado de uma imagem suja ou de um som abafado se tornam possibilidades de trabalho e diálogo para criação de novas obras que fundem tecnologias e escapam dos lugares convencionais. Ao lado de alta tecnologia dos softwares e do Macintosh, mecanismos low tech e a baixa definição são otimizados por alguns performers, gerando imagens que através do desconforto e do encobrimento de obras protegidas pelo direito autoral podem ser manipuladas em seus sets de apresentação justamente pela descaracterização da qualidade. Essa técnica advém do scratch. Um exemplo: muitos arquivos de filmes pixelados encontrados no Youtube são mais "arranhados", descaracterizados para serem utilizados em performances. Muitas vezes acabamos usando versões com "imagens sujas" em aula. Era justamente essa técnica de distorcer completamente a imagem que o VJ nos analógicos anos 1980 já começava a aplicar em seguidos momentos de sua apresentação e que recebeu um elogio pelo vídeo artista.

Talvez seja necessário mais e mais distorcer e fazer circular em loops nossa visão da sala de aula para os temas que tentamos brevemente aqui sugerir. O ensino a distância ganha terreno e a física da sala de aula precisa de novas aberturas, de novos espaços e de um uso mais ativo, interativo, instalativo e imersivo no contemporâneo estranho aos próprios tempos como o Nietzsche educador sentia e como creio muitos de nós professores da civilização da imagem (e do som) ainda sentimos no eterno retorno às salas de aula dia após dia.

\section{REFERÊNCIAS}

AGAMBEN, Giorgio. 0 que é o contemporâneo? e outros ensaios. Chapecó: Argos, 2009.

ARMES, Roy. On vídeo. 2. ed. São Paulo: Summus, 1998.

AUMONT, Jacques. Moderno: Por que o cinema se tornou a mais singular das artes? Campinas, SP: Papirus, 2008.

BAL, Mieke. Setting the stage: The subjective mise en scène. In: DOUGLAS, Stan; EAMON, Christopher (eds.). Art of projection. Ostfieldern: Hatje Cantz, 2009.

BAZIN, Andre. 0 cinema: ensaios. São Paulo Brasiliense, 1991.

BENJAMIN, Walter. Obras escolhidas. São Paulo: Brasiliense, 1994. Vol. I.

BERGSON, Henri. A evolução criadora. São Paulo: Martins Fontes, 2005.

BRASSAÏ, Gilberte. Proust e a fotografia. Rio de Janeiro: JZE, 2005.

COURI, Aline. Loop: tecnologia e repetição na arte. Rio de Janeiro: Editora Torre, 2012.

FERREIRA, Jairo. Críticas de invenção: os anos do São Paulo Shimbun. São Paulo: Imprensa Oficial, 2006.

GUMBRECHT, Hans Ulrich. Produção de presença: o que o sentido não consegue transmitir. Rio de Janeiro: Contraponto, 2010.

KEEN, Andrew. 0 culto do amador. Rio de Janeiro: Jorge Zahar Ed., 2009.

MACHADO, Arlindo. Máquina e imaginário: 0 desafio das poéticas digitais. São Paulo: Edusp, 1993.

-_-_-_. Regimes de imersão e modos de agenciamento. In: MACIEL, Katia (org.). Transcinemas. Rio de Janeiro: Contracapa, 2009.

MANOVICH, Lev. The language of new media. Massachussets: The Mit Press, 2001.

MCLUHAN, Marshall. Os meios de comunicação como extensões do homem. São Paulo: Cultrix, 1964. 
; MCLUHAN, Eric. The laws of media.

Toronto: University of Toronto, 2000.

MELLO, Christine. Extremidades do vídeo. São Paulo: Senac, 2008.

NIETZSCHE, Friedrich. Escritos sobre educação. São Paulo: Loyola, 2003.

RANCIÈRE, Jacques. As distâncias do cinema. Rio de Janeiro: Contraponto, 2012.

RUSH. Michael. Novas mídias na arte contemporânea. São Paulo: Martins Fontes, 2006.

SALIS, Fernando. Cinema (ao) vivo: A imagem performance. In: MACIEL, Katia (org.). Transcinemas. Rio de Janeiro: Contracapa, 2009.

SANTAELLA, Lúcia. Panorama da arte tecnológica. In: LEÃO, Lucia (org.). 0 chip e o caleidoscópio: reflexões sobre as novas mídias. São Paulo: Senac, 2005.

PARENTE, André. Cinemáticos. Rio de Janeiro: +2 Editora, 2013.

SHAW, Jeffrey. O cinema digitalmente expandido: o cinema depois do filme. In: LEÃO, Lucia (org.). 0 chip e o caleidoscópio: reflexões sobre as novas mídias. São Paulo: Senac, 2005.

SERRES, M. Hominescências, Rio de Janeiro: Bertrand Brasil, 2003.

YOUNGBLOOD, Gene. Expanded cinema. New York: E.P. Dulkton \& Co, 1970.

\section{SOBRE O AUTOR}

Wilson Oliveira Filho é graduado em Comunicação Social, especialista em Filosofia Contemporânea, Mestre em Comunicação e Cultura e doutorado em Memória Social com período sanduíche no curso de Cinema and Media Studies da Universidade de Chicago sob supervisão de Tom Gunning. Atualmente é professor auxiliar da Universidade Estácio de Sá nos cursos de graduação em Comunicação Social, Produção Audiovisual e Cinema e Audiovisual e em cursos de pósgraduação lato sensu, além de professor substituto de Linguagem Audiovisual I no departamento de Expressão e Linguagens ECO/UFRJ. Sua atual pesquisa é sobre live cinema, cidade e projeção.
É membro da Associação Brasileira de Educação a Distância (ABED), da Sociedade Brasileira de Estudos de Cinema e Audiovisual (SOCINE) um dos coordenadores do Seminário temático “Exibição cinematográfica, espectatorialidade e artes da projeção no Brasil" - e da Media Ecology Association (MEA). Entre julho de 2012 e 2013 assumiu a coordenação do curso de Cinema da UNESA - campus João Uchoa. Como artista, desenvolve trabalhos multimídia e outros produtos audiovisuais com o Duo $2 \times 4$. 